\title{
LA QUIJOTIZACIÓN DE SANCHO Y LA AUTOORGANIZACIÓN DE LOS SISTEMAS*
}

\author{
José Manuel Martín Morán \\ Università del Piemonte Orientale \\ martin.moran@uniupo.it
}

$\mathrm{L}$

a actuación de Sancho en el gobierno de Barataria es, sin duda alguna, el momento culminante de lo que buena parte de la crítica ha visto como su proceso de crecimiento. En la ínsula, el rústico escudero de don Quijote hace gala de unas dotes naturales para el gobierno que le granjean el amor y el respeto de los miembros de la comunidad: «Quedaron todos admirados, y tuvieron a su gobernador por un nuevo Salomón» (II, 45) ${ }^{1}$. Además de este desmesurado elogio del ex pastor de cabras, se hallan desperdigadas por el texto de los capítulos dedicados a la ínsula otras valoraciones de su buen hacer que no dejan lugar a dudas sobre su encumbramiento; he aquí unos ejemplos:

Los circunstantes quedaron admirados de nuevo de los juicios y sentencias de su nuevo gobernador (II, 45).

Todos los que conocían a Sancho Panza se admiraban oyéndole hablar tan elegantemente y no sabían a qué atribuirlo, sino a que los oficios y cargos graves o adoban o entorpecen los entendimientos (II, 49).

- Cuando esperaba oír nuevas de tus descuidos e impertinencias, Sancho amigo, las oí de tus discreciones, de que di por ello gracias particulares al cielo, el cual del estiércol sabe levantar los pobres, y de los tontos hacer discretos (II, 51).

No cabe duda de que sus acciones y la consideración de las mismas por los demás personajes, amén del propio gobierno de la ínsula, tantas veces prometido por don Quijote, constituyen una forma de glorificación del personaje del escudero.

\footnotetext{
Este trabajo se inscribe en el marco del proyecto de investigación FAR 2019 «Trasposizioni e riscritture (XVI-XX secolo)» financiado por la Università del Piemonte Orientale.

1 He utilizado la edición online del Quijote del Instituto Cervantes, dirigida por Francisco Rico $<$ http://cvc.cervantes.es/literatura/clasicos/quijote/>.
}

Edad de Oro, XL (2021), pp. 301-325, ISSN: 0212-0429 - ISSNe: 2605-3314

DOI: https://doi.org/10.15366/edadoro2021.40.015 
Pero ¿a costa de qué? El Sancho, cuya sabiduría, discreción y aplomo alabamos en este episodio, es casi irreconocible para los lectores del Quijote de 1605; más bien se diría que es incluso incongruente con los atributos que lo caracterizaban diez años atrás. De aquel Sancho queda - ¿cómo no? - el hambre atávica o, por mejor decir, su glotonería y falta de moderación con la comida, de la que hace escarnio el cruel médico Pedro Recio de Tirteafuera, cuando hace retirar de la mesa, uno por uno, los manjares sobre los que ha caído la mirada deseante del hambriento gobernador; el amor por los refranes, sobre los que se fundan algunos de sus juicios; la campechanía, que antes era rustiquez y ahora, con el cargo, se ha transformado en una especie de versión plebeya de la sprezzatura que Castiglione aconsejaba al cortesano:

Fuggir quanto più si po, e come un asperissimo e pericoloso scoglio, la affettazione; e, per dir forse una nova parola, usar in ogni cosa una certa sprezzatura, che nasconda l'arte e dimostri ciò, che si fa e dice, venir fatto senza fatica e quasi senza pensarvi (1965: I, 26, 44).

En la traducción de Boscán suena así:

Huir cuanto sea posible el vicio que de los latinos es llamado afetación; nosotros, aunque en esto no tenemos vocablo proprio, podremos llamarle curiosidad o demasiada diligencia y codicia de parecer mejor que todos. Esta tacha es aquella que suele ser odiosa a todo el mundo; de la cual nos hemos de guardar con todas nuestras fuerzas, usando en toda cosa un cierto desprecio o descuido, con el cual se encubra el arte y se muestre que todo lo que se hace y se dice, se viene hecho de suyo $\sin$ fatiga y casi sin habello pensado (1994: I, 26, 143-144).

Y en el precepto de la sprezzatura parecería inspirarse el Sancho recién llegado a la ínsula - pero no hay que olvidar el peso de los consejos de su amo e incluso su propia índole-, que renuncia a cualquier forma de afectación en los tratamientos cuando le leen el rótulo de la pared:

-Y ¿a quién llaman don Sancho Panza? — preguntó Sancho.

- A vuestra señoría — respondió el mayordomo-, que en esta ínsula no ha entrado otro Panza sino el que está sentado en esa silla.

— Pues advertid, hermano — dijo Sancho-, que yo no tengo don, ni en todo mi linaje le ha habido: Sancho Panza me llaman a secas, y Sancho se llamó mi padre, y Sancho mi agüelo, y todos fueron Panzas, sin añadiduras de dones ni donas (II, 45).

Claro que en el magnífico gobernador capaz de hacer constituciones que quedarán en la memoria de Barataria, dictar sentencia en complicadísimos casos de justicia y comportarse con el «desprecio» y el «descuido» del aristócrata más político, por debajo de esa pátina necesaria, aún pervive la parte «dura», caracterial, 
pasiva, del labrador a la defensiva contra los abusos del poder, acostumbrado a ser mandado y no a mandar, y resignado a no tener autonomía. En él, la sprezzatura cortesana se confunde con la desconfianza y la ataraxia existencial del labrador acostumbrado a los zarandeos del poder y a la exclusión social. La campechanía que demuestra en el rechazo del «don», los refranes y, si se me apura, hasta la astucia con que desmonta algunos casos listos para sentencia, son, al fin y al cabo, virtudes de repliegue, desarrolladas por quien no puede permitirse la práctica de las virtudes sociales de los poderosos. La campechanía es la versión humilde del sosiego y el «desprecio» boscaniano; los refranes, del saber humanístico; y la astucia, del conocimiento de las leyes; son todos ellos, en una palabra, otras tantas formas de renuncia a instalarse en unos terrenos de la identidad social que sabe inhabitables para él. En ese sentido, desde la lógica narrativa, la sprezzatura plebeya de la que hace gala el Sancho insulano evita el engolosinamiento con el poder y una transformación de su personalidad que habrían hecho inviable su retorno a los moldes del siervo. Pero en los episodios de la ínsula él ya no es el títere movido por hilos ajenos; ahora es capaz de tomar la iniciativa y dejar bien claras sus dotes y su intención de cambiar el mundo; ahora, además de ser el gobernador de sus súbditos, se ha hecho gobernador de sí mismo. Este aspecto de su personalidad insulana, la parte activa de su sistema de atributos, es justamente la que resulta incongruente con aquel Sancho de diez años atrás que comulgaba con todas las ruedas de molino que su amo le iba suministrando, así fuera después de un primer momento de escepticismo, y que daba por reales los encantadores, los bálsamos milagrosos, las princesas Dulcinea y Micomicona, las ínsulas, etc.

Tampoco las actuaciones de Sancho en los episodios anteriores al del gobierno hacían presagiar el excelente desenvolvimiento en Barataria; en efecto, no cabía esperar finuras de leguleyo de quien pedía sin asomo de ironía «una tantica parte del cielo» (II, 42) al mismo duque que le estaba mandando a gobernar una de sus posesiones en la tierra; $y$, poco antes, se dejaba convencer por la duquesa de que Dulcinea estaba realmente encantada (II, 33), a pesar de que el artífice del supuesto encantamiento había sido él y, por tanto, debía de saber muy bien que nunca había tenido lugar. Tampoco el comportamiento de Sancho en los episodios posteriores al de la ínsula parece coherente con las sentencias de marras, si es capaz de dejarse engatusar por el derrotado don Quijote para que emprendan vida de pastores durante el año de abstinencia aventurera que le ha impuesto el caballero de la Blanca Luna y de aconsejar al moribundo don Quijote: «-No se muera vuestra merced, señor mío, sino tome mi consejo y viva muchos años, porque la mayor locura que puede hacer un hombre en esta vida es dejarse morir, sin más ni más, sin que nadie le mate» (II, 74).

Es cierto que el personaje de Sancho se mueve entre los dos extremos del oxímoron tonto / listo, como don Quijote entre los del loco / cuerdo (Socrate, 1974: 
40), y que todas las acciones y dichos aludidos hasta aquí cabrían en ese inmenso espacio de actuación; pero el decoro del personaje impondría la reducción del espacio actancial a una zona donde las dos cualidades no sean incompatibles, como creo que sucede entre el consejo final a don Quijote y la petición al duque, por un lado, y las justamente alabadas sentencias de la ínsula.

Mi opinión sobre la infracción al decoro por parte del Sancho de Barataria no es la de la mayor parte de la crítica, que por lo general ha visto en esta perspicacia del escudero una de las manifestaciones de su quijotización, proceso en acto ya desde el principio del Quijote de 1615. La idea de que la evidente evolución de Sancho entre la primera y la segunda parte sea debida al influjo de don Quijote es un tópico de la crítica cervantina, al menos desde que Madariaga (1947: 165-191) la formulara en los años veinte del siglo pasado; reaccionaba así don Salvador a la neta contraposición romántica entre el caballero del ideal y el escudero materialista, dignificada por Toffanin (1920: 211-221) en clave neoaristotélica cuando identificaba el motor profundo de los dos protagonistas en el binomio poesía / historia. Madariaga seguía la estela trazada por Savj-López (1913: 92, 94 y 105) y su idea de la lenta evolución de Sancho y su radical diferencia de don Quijote. La tesis de Madariaga ha tenido una notable fortuna entre los críticos, gracias a su reelaboración por Dámaso Alonso (1962: 9-19) y otros, entre los que destaca recientemente Dotras Bravo (2008); otro sector de la crítica se opone a la interpretación de la transformación de los personajes del Quijote como el resultado de un doble proceso de quijotización para Sancho y de sanchificación para don Quijote con el argumento de que entre 1605 y 1615 no se produce un verdadero crecimiento de los personajes, sino una transformación repentina (Sletsjöe, 1961; Russell, 1969; Martínez Bonati, 1978; Martín Morán, 1992).

En las páginas siguientes propongo una perspectiva crítica un tanto diferente de la actuación del gran gobernador de Barataria, analizando sus comportamientos no como ocurrencias únicas, ni como elementos de una serie, sino como componentes de varios sistemas interrelacionados que se definen y se perfilan de manera diferente en cada contexto, según las relaciones con los otros componentes y según las modificaciones de su equilibrio interno.

\section{NACIMIENTO DE UN BINOMIO}

Un aspecto en el que básicamente todos los críticos que se han ocupado de la relación entre don Quijote y Sancho coinciden es en el hecho de que forman un binomio casi inescindible. Hay incluso quien lleva la idea a sus consecuencias extremas y sostiene que se trata, en realidad, de un solo personaje (Sánchez Rivero, 1927: 293 y ss.; Molho, 1976: 255). En efecto, casi no es concebible don Quijote sin Sancho y viceversa; como tampoco lo son sus acciones, si no es en el 
interior de un complejo de dinámicas relacionales con el entorno social. Las valencias del personaje de don Quijote resaltan en su oposición a las de Sancho y, al contrario, las de Sancho en oposición a las de don Quijote; lo cual equivale a decir que el uno y el otro adecúan sus actos y dichos al tipo de respuesta que reciben de su interlocutor; por la misma regla de tres, su elevación a unos niveles de inteligencia y prudencia superiores en el Quijote de 1615 respecto a las cotas alcanzadas en 1605 podría depender también de las reacciones de la pareja a los estímulos del ambiente, lo que puede llevarnos a sospechar que las pretendidas evoluciones de los protagonistas son, en realidad, estrategias de adecuación elaboradas por el autor, para que ambos puedan responder a las nuevas exigencias del sistema del que forman parte.

Sobre la falsilla de la relación caballero / escudero de los libros de caballerías, pero también sobre la de amo / criado del folklore (Molho, 1976: 215-336; Redondo, 1978) de tantas obras dramáticas (Alonso, 1962; Díaz-Plaja, 1977: 81-162; Syverson-Stork, 1986) y de la literatura en general - aunque tampoco hay que desdeñar el modelo de la realidad social contemporánea (Close, 2001; Martín Morán, 2004)—, Cervantes propone una estructura binaria capaz de elaborar cualquier estímulo externo en una doble perspectiva: por un lado, la dimensión transitiva de la acción diegética, fruto de la respuesta a la incitación exógena y, por el otro, la dimensión reflexiva de la corrección del equilibrio interno del binomio en aras de una mayor eficacia en su interacción con el mundo. De tal modo, la estructura de dos elementos en tensión continua se retroalimenta positivamente a partir del estímulo exterior, al que ofrece una respuesta inmediata, mientras utiliza una parte de la energía de la respuesta para modificar su equilibrio interno; así es como en la teoría de los sistemas se define el fenómeno de la retroalimentación positiva (Watzlawick, Helmick Beavin y Jackson, 1985: 32-33; Åström y Murray, 2008: 1-3).

He aquí una actualización de las dinámicas apenas descritas en el ejemplo canónico: en el episodio de los molinos de viento, los dos oxímoros andantes (el loco / cuerdo y el tonto / listo) elaboran en el interior del binomio la doble esencia (gigantes / molinos) del elemento externo con una discusión en la que el componente loco de don Quijote trata de asimilar a su postura al componente listo de Sancho, sin llegar a convencerle de que son gigantes; cuando el polo cuerdo del caballero, tras la dolorosa derrota por obra de unas aspas caprichosas, se percate de que el polo listo de Sancho siente más la fuerza de atracción de la interpretación realista («los gigantes son molinos»), volverá a ceder su espacio al núcleo loco de su microsistema para imponer al otro la creencia en la intervención de los encantadores, sin que el criado pueda oponerse a su fuerza centrípeta, aun a costa de ver transformada su pasajera listura en tontería. De tal modo, el binomio de los dos microsistemas encuentra un nuevo equilibrio homeostático, fundado en la restauración de los dos polos deficientes (locura y simpleza), que le permitirá 
afrontar cualquier otro estímulo real con una dinámica parecida, sin tener que recurrir de nuevo a los rudimentos de la enciclopedia caballeresca, puesto que estos ya habrán sido asimilados por los dos microsistemas; de todo ello resultará, por un lado, la producción de materia diegética y, por el otro, el reforzamiento de la capacidad resiliente del binomio.

La reacción en cadena que acabo de exponer podría haberse roto, si el segundo microsistema se hubiera resistido a la atracción final de la fuerza centrípeta del otro hacia el polo loco, negando la existencia de los encantadores, pero eso habría equivalido a negar la autoridad de don Quijote en materia caballeresca que es la base de su relación complementaria (Watzlawick, Helmick Beavin y Jackson, 1985: 68-71), la energía orbitante que une los dos sistemas, con lo que habría tenido que negar también su fe en la ínsula prometida y deshecho el binomio (Martín Morán, 2004). En última instancia, la fuerza que mantiene la cohesión del sistema es la voluntad de ser de don Quijote, que presiona activamente sobre el elemento inerte que es la voluntad de creer de Sancho, conformando una especie de membrana protectora hacia el entorno que encierra al binomio en sus dinámicas internas.

Claro que, si bien se mira, para explicar la interrelación entre amo y escudero no basta la lógica de la retroalimentación, pues no todos los estímulos tienen repercusión en el binomio y no todas las interacciones entre los dos microsistemas son respuestas a estímulos externos, ni tampoco todas producen alteraciones del equilibrio. Es necesario que los vectores de la modificación hacia el exterior o hacia el interior se circunscriban a un campo semántico específico, que es el mundo caballeresco con todos sus anexos: amor cortés, sentido del honor, concepción mágica del mundo, relaciones de vasallaje y pupilaje, etc.

De estos elementos ideológicos que conforman el coto cerrado de los valores de don Quijote, sobre los que está dispuesto a medirse con cualquiera y en cualquier circunstancia, se derivan unas aptitudes que, como otros tantos «gestos», definen la fisionomía comportamental del caballero: retórico orador, soñador utópico, melancólico depresivo, enamorado fiel, etc. Tanto la ideología de don Quijote, como sus aptitudes «gestuales» se enfrentan a la ausencia de ideología de Sancho, a sus actitudes renunciatarias; de ahí surgen situaciones caracterizadas, por lo general por un primer momento de rechazo a los «gestos» del amo por parte del siervo que los rebaja a los niveles de su apego a la tierra y lo material, para en un segundo momento dejarse contaminar y emprender él también el vuelo en las alas del ideal.

\section{IDENTIDAD SIN OXÍMOROS}

En realidad hay otro campo semántico en el que el caballero loco desarrolla unas aptitudes especiales, que es el de la necesidad de ser un personaje literario; tal ámbito aparece apenas esbozado en 1605, cuando imagina incluso las palabras 
concretas con que su futuro historiador se imaginará su primera salida por el campo de Montiel:

— ¿Quién duda sino que en los venideros tiempos, cuando salga a luz la verdadera historia de mis famosos hechos, que el sabio que los escribiere no ponga, cuando llegue a contar esta mi primera salida tan de mañana, desta manera?: "Apenas había el rubicundo Apolo tendido por la faz de la ancha y espaciosa tierra las doradas hebras de sus hermosos cabellos...» $(\mathrm{I}, 2)$.

En 1615, en cambio, después de que Sansón Carrasco le lleve la noticia de la publicación del libro de 1605, su afán de transcendencia literaria futura se ha transformado en una realidad presente incontrovertible, que genera en él la conciencia de ser un personaje literario y el comprensible orgullo por hallarse ya en estampa; así concluye su presentación con el caballero del Verde Gabán: «-Treinta mil volúmenes se han impreso de mi historia, y lleva camino de imprimirse treinta mil veces de millares, si el cielo no lo remedia» (II, 16). Claro que las aptitudes que derivan del afán literario de don Quijote son difícilmente separables de las que provienen del ámbito caballeresco; el honor que glorifica al héroe de las caballerías, en la mente de don Quijote, no es muy distinto de la fama que su condición de personaje libresco le procura.

Ahora bien, esto no quiere decir que otros elementos fuera de los dos campos acotados no existan o que ocasionalmente no puedan ser también productivos para el relato. En realidad, como todo el mundo sabe, la composición de los dos microsistemas es más compleja de lo apuntado. Los dos personajes poseen otros atributos fuera del oxímoron central que los opone al otro, que son, tal vez, los que los hacen más completos a los ojos del lector, más redondos, en una palabra, más reconocibles como paradigmas de humanidad. En el caso de don Quijote esas cualidades son las que, de algún modo, niegan las líneas de comportamiento fundamentales, pues de concederles espacio lo desconstituirían como aspirante a caballero; sustancialmente se reducen a unos pocos restos de la mentalidad pragmática del hidalgo de aldea que son los que le hacen volver a probar la celada $(\mathrm{I}, 1)$ o rebajar a Dulcinea a instrumento necesario para su acción $(\mathrm{I}, 25)$ o ver las ensoñaciones desacralizadoras de la cueva de Montesinos (II, 23) o padecer las necesidades fisiológicas impolutas en la primera venta (I, 2) y no tanto en el carro de vuelta a casa, cuando el caballero pide ayuda a Sancho con estas sentidas palabras: «¡Sácame deste peligro, que no anda todo limpio!» (I, 48). Las acciones derivadas de esta segunda área de atributos no construyen el currículum caballeresco, como podrían hacer las otras, con todos sus problemas de interpretación correcta de lo vivido y de evaluación final del resultado obtenido, sino otro paralelo y subsumido a tanta gloria que propone más la personalidad de un personaje de entremés o de farsa narrativa. 
Una vez aclarada la interacción en el binomio y del mismo con el entorno, desplazaremos el foco de nuestra atención a la evolución del triple sistema a lo largo de la novela, en sus diferentes fases.

\section{EvOLUCIÓN DEL BINOMIO}

Antes de la constitución del binomio, es decir, antes de que Sancho entrara en escena, en la primera salida de don Quijote, era el propio caballero el que recubría algunas de las funciones cómicas que luego serán de su escudero, con la urgencia por satisfacer su hambre o sus chistes sobre la comida:

Preguntáronle si por ventura comería su merced truchuela, que no había otro pescado que dalle a comer.

- Como haya muchas truchuelas — respondió don Quijote—, podrán servir de una trucha, porque eso se me da que me den ocho reales en sencillos que en una pieza de a ocho. Cuanto más, que podría ser que fuesen estas truchuelas como la ternera, que es mejor que la vaca, y el cabrito que el cabrón (I, 2).

En estos primeros capítulos, la estrategia de marcación de su locura pasaba por su descalificación a cargo del narrador («el sol entraba tan apriesa y con tanto ardor, que fuera bastante a derretirle los sesos, si algunos tuviera» [I, 2]) y el encontronazo violento o la reacción de total extrañeza de los personajes con los que se topaba; el resultado era el de un personaje sin facetas, con una sola dimensión enajenada, o poco más, que lo alejaba de la interacción racional con los demás; la capacidad oratoria que lo caracterizará en la segunda salida, a partir del encuentro con los cabreros (I, 11), aún no le proporciona, en esta primera, la posibilidad del intercambio dialéctico en las ocasiones convivales.

La llegada de Sancho, o sea, la constitución del binomio, proporciona a don Quijote un interlocutor constante para sus observaciones sobre el mundo, sus percepciones aberrantes, sus ilusiones, sus preceptos, sus proyectos, sus amores; el narrador podrá tomar la adecuada distancia, ya sin la urgencia de la reprobación del loco de la primera salida: Sancho servirá de piedra de toque constante de la locura del hidalgo. Así pues, el sistema de la primera salida, que preveía el conflicto abierto, verbal o de actos, entre el loco andante y sus interlocutores, con un observador externo, el narrador, que tomaba posición contra su protagonista, con la inclusión del escudero, mantiene su equilibrio y su efectividad en parodiar la figura del novel caballero andante, pero en su reajuste atribuye a Sancho funciones que eran propias de otros personajes, como la de generar diálogos o situaciones cómicas sobre la comida, que antes, como hemos visto, en alguna ocasión, corría a cargo del propio don Quijote; o la incompatibilidad de códigos lingüísticos que explicaba la reacción de las mozas del partido (I, 2), los mercaderes de Toledo (I, 4), 
Juan Haldudo (I, 4) o Pedro Alonso (I, 5) ante las peroraciones anacrónicas, con pretensiones imperativas y propuestas de identidades alternativas que les hace don Quijote; o la atención al cuerpo del caballero de las mozas del partido, cuando le ayudan con exquisita diligencia a trincar el vino por una cánula (I, 2), o la del samaritano Pedro Alonso que lo recoge del suelo y lo lleva hasta su casa (I, 5).

La inclusión de un elemento nuevo en los estratos superiores del sistema conlleva la concentración de funciones en él, a expensas de otros personajes, como si se tratara de una especie invasora en un nicho ecológico frágil; en este caso, la inclusión del voraz invasor Sancho Panza tiene también una recaída positiva en el debilitamiento de la membrana externa que encerraba las situaciones narrativas en una síntesis semántica a cargo del narrador — por ejemplo, bajo forma de descalificaciones del andante ido-; la continua interacción dialógica entre Sancho y su amo, en un ámbito privado, segregado del sistema general, expone a la contemplación y el juicio del observador los modos de comprensión del mundo de los personajes; el binomio muestra sus dinámicas internas y esto enriquece ulteriormente el macrosistema de la comunicación literaria entre la obra y el contexto sociocultural de su recepción.

Los modos de interacción entre la entidad protagonista y los demás personajes se amplían con la llegada de Sancho, como es lógico, pero además, con el diálogo entre los dos errantes anterior y posterior a la acción, se constituye un nivel superior del sistema en el que la relación interna del binomio se retroalimenta del sentido de los hechos — lo decía hace un momento - , transformando continuamente cada uno de los elementos sobre la base de la experiencia compartida. La importancia de esa retroalimentación se percibe en las reiteraciones de los contenidos, cuando ambos vuelven sobre un tema o un episodio ya tratados para matizar algún aspecto o tratar de alterar el equilibrio interno del binomio; Sancho utilizará varias veces el recuerdo de sus padecimientos físicos como resultado de los alardes caballerescos de su amo, para amenazar con abandonarlo o para tratar de sacar un mayor beneficio personal; y así el manteamiento, los palos recibidos, el hambre, los encantadores serán unas constantes del diálogo sobre las que se irá construyendo la relación entre los dos andantes.

\section{Problemas de inestabilidad Del Sistema}

La estabilidad del binomio es sometida a duras pruebas en diferentes ocasiones y casi siempre por deficiencias en la membrana autoritaria que lo protege. A veces, el carisma de don Quijote no consigue evitar que las agresiones de los elementos externos se ensañen con el otro microsistema, como en el episodio del manteamiento ( $\mathrm{I}, 17)$, y por eso este reclama y amenaza con disolver la simbiosis volviéndose a casa $(\mathrm{I}, 18)$. Otras veces, la autoridad revierte sobre las 
dinámicas internas del binomio, y así, por ejemplo, don Quijote impone moderación cuantitativa en el habla (I, 20) a un Sancho que termina por no aceptarlo y exigir cambios, so pena, esta vez también, de escindir la unión (I, 25). Otras veces aún, es Sancho el que tensa la relación con su amo, agrediendo desde el interior a uno de los componentes del microsistema de su amo, como cuando se burla de su retórica caballeresca en la aventura de los batanes (I, 20) o le sugiere que abandone la fidelidad a Dulcinea para aprovechar la ocasión que le ofrece Micomicona (I, 30) o le revela que la susodicha princesa se besa por los rincones con un recién llegado a la venta, demostrando así bien poca realeza (I, 37). Dos buenos palos en las espaldas de Sancho con el lanzón de don Quijote, en los dos primeros casos, y una airada reprimenda en el tercero, devolverán al binomio un equilibrio renovado.

El estrés del sistema binario se manifiesta en síntomas que cambian su aspecto externo; al igual que la modificación en los componentes de la atmósfera produce el calentamiento del clima, así las tensiones entre amo y criado producen alteraciones físicas en el primero o cambios en los tratamientos: si don Quijote abandona el «tú» y pasa al «vos», mala señal para Sancho. Claro que nunca tuvo don Quijote una alteración tan fuerte como la que le produce descubrir que Sancho ha calumniado a Micomicona con el chisme de los besos a escondidas: «Enarcó las cejas, hinchó los carrillos, miró a todas partes, y dio con el pie derecho una gran patada en el suelo, señales todas de la ira que encerraba en sus entrañas» (I, 46).

Otro momento delicado para la unidad amo / criado se verifica cuando, aprovechando una debilidad contractual de Sancho que pretende salario por sus servicios, se postula a sustituirlo el mismísimo Sansón Carrasco; de haberse producido la sustitución, el estudiante de Salamanca habría puesto en peligro la estabilidad del sistema, a causa de su superior inteligencia, lo que, por supuesto, habría hecho inviables muchos de los diálogos entre amo y escudero. En otras palabras: la capacidad del postulante de desarrollar unas funciones a un nivel superior en la jerarquía del sistema habría puesto en peligro la subsistencia del mismo; afortunadamente la competencia por el puesto es ganada por Sancho, a costa de renunciar a su reivindicación sindical, y eso garantiza la estabilidad y la pervivencia del conjunto.

A modo de corolario de la argumentación anterior, podríamos afirmar que, en el Quijote de 1605, el binomio protagonista mantiene una gran estabilidad, sin necesidad de modificar los componentes de cada microsistema, gracias a su capacidad de resiliencia frente a las agresiones del entorno y a su versatilidad en la consecución de diferentes equilibrios homeostáticos; pero ¿qué sucederá cuando las amenazas al sistema vengan, no del entorno inmediato, sino de ámbitos más alejados y potentes? Tendremos la oportunidad de comprobar su capacidad de reacción en la segunda parte de la obra. 


\section{EL BINOMIO EN 1615}

En el Quijote de 1615, el macrosistema del texto reacciona contra dos fuertes traumas producidos por fuentes externas, extratextuales y, por tanto, vinculadas no ya a la ficción sino al contexto histórico-cultural de la obra. La reacción a las dos agresiones va a implicar la alteración de las funciones y los equilibrios internos de los diferentes microsistemas que componen el texto en sus varios niveles. En 1605, el proceso de autoorganización de los sistemas como consecuencia del influjo del entorno no transcendía los límites del relato; tanto las agresiones como la reacción subsiguiente tenían dimensión intratextual. Ahora, el relato modifica sus estructuras funcionales sobre la base de elementos del mundo real, por más que estén ligados ambos al campo literario (Bourdieu, 1992), pues se trata, como ya se habrá adivinado, en primer lugar, de la elaboración en 1615 de la noticia de la publicación, difusión y recepción del Quijote de 1605, y, en segundo lugar, de la del Quijote de Avellaneda, a la altura del capítulo II, 59.

En los primeros capítulos de la obra de 1615, Sansón Carrasco expone sucintamente ante don Quijote y Sancho los aspectos principales de la recepción del Quijote de 1605, subrayando la buena acogida general por parte del público lector, sin ocultar, empero, las críticas: los protagonistas reciben demasiados palos, el libro contiene relatos secundarios sin conexión alguna con la trama principal y, además, por si fuera poco, en él no se cuenta el uso de los cien escudos hallados por Sancho en Sierra Morena ni las circunstancias del robo y la reaparición del rucio (II, 3-4). En la respuesta de Cervantes a estas críticas de los lectores se verán implicadas varias instancias de diferentes niveles del relato o, dicho con la jerga que hoy me domina, varios elementos pertenecientes a diversos microsistemas jerarquizados entre sí. En corto y por derecho, Cervantes decide responder con palabras de Sancho a los dos últimos reparos y reducir el número y el tamaño de los relatos secundarios para solventar su dificultad de ensamblado en el principal, atribuyendo la decisión a Cide Hamete, el autor ficticio (II, 44). Para resolver la cuestión del exceso de violencia como solución a las situaciones de conflicto, la operación será un poco más complicada.

La decisión de acoger en el mundo de la ficción las reacciones de los lectores reales y adecuar el nuevo texto a ello, como era fácil de prever, modifica el macrosistema narrativo en todos sus niveles. Empezando por los componentes más íntimos de la personalidad de los protagonistas; el doble conjunto de semas en equilibrio, con ser antitéticos algunos, que garantizaba la relación entre ambos, se modifica en las proporciones y se enriquece con nuevas adquisiciones. Mientras espera que Sancho vuelva con Sansón Carrasco, don Quijote se enfrenta a la imagen de sí mismo en el libro publicado, o mejor, a sus conjeturas solitarias sobre ella: 
Imaginó que algún sabio, o ya amigo o enemigo, por arte de encantamento las habrá dado [sus altas caballerías] a la estampa: si amigo, para engrandecerlas y levantarlas sobre las más señaladas de caballero andante; si enemigo, para aniquilarlas y ponerlas debajo de las más viles que de algún vil escudero se hubiesen escrito, puesto - decía entre sí- que nunca hazañas de escuderos se escribieron; y cuando fuese verdad que la tal historia hubiese, siendo de caballero andante, por fuerza había de ser grandílocua, alta, insigne, magnífica y verdadera. Con esto se consoló algún tanto, pero desconsolóle pensar que su autor era moro, según aquel nombre de Cide; y de los moros no se podía esperar verdad alguna, porque todos son embelecadores, falsarios y quimeristas. Temiese no hubiese tratado sus amores con alguna indecencia, que redundase en menoscabo y perjuicio de la honestidad de su señora Dulcinea del Toboso; deseaba que hubiese declarado su fidelidad y el decoro que siempre la había guardado, menospreciando reinas, emperatrices y doncellas de todas calidades, teniendo a raya los ímpetus de los naturales movimientos (II, 3).

El reflejo imaginado de su persona en las páginas de 1605, la contraposición de la percepción que tiene de sí mismo en el presente, de sus hazañas y comportamientos en el pasado, con las dudas acerca de su tratamiento en manos ajenas le otorga una conciencia de sí, surgida de la escisión del yo del resto del yo (Freud, 1978: 235), que hasta entonces no poseía: la de saberse objetivado en la mente de un autor y en las apreciaciones de unos lectores; ya no es solo lo que es y lo que quiere ser, sino también lo que los otros creen que es.

En la discusión con el estudiante de Salamanca, los dos errantes argumentan en pro de la cohesión del libro de diez años antes, justificando y explicando el descuido del burro, y proponiendo conceptos como el de poesía e historia como parámetro de comprensión del texto:

—Con todo eso — respondió el bachiller-, dicen algunos que han leído la historia que se holgaran se les hubiera olvidado a los autores della algunos de los infinitos palos que en diferentes encuentros dieron al señor don Quijote.

- Ahí entra la verdad de la historia — dijo Sancho.

— También pudieran callarlos por equidad — dijo don Quijote—, pues las acciones que ni mudan ni alteran la verdad de la historia no hay para qué escribirlas, si han de redundar en menosprecio del señor de la historia. A fee que no fue tan piadoso Eneas como Virgilio le pinta, ni tan prudente Ulises como le describe Homero.

—Así es — replicó Sansón-, pero uno es escribir como poeta y otro como historiador: el poeta puede contar, o cantar las cosas, no como fueron, sino como debían ser; y el historiador las ha de escribir, no como debían ser, sino como fueron, sin añadir ni quitar a la verdad cosa alguna (II, 3).

Se comportan en esto no como personajes del libro, sino como prologuistas del mismo; se salen de la trama, para situarse en un punto de observación elevado, y 
transmitir al lector unas instrucciones de lectura (Genette, 2001: 168) y una posible clave de interpretación del texto. Su autoconciencia los ha dotado de una función añadida: la «función prologal», que ejercerán puntualmente en otros momentos del libro de 1615, sobre todo, cuando les toque defender la autoría cervantina frente al apócrifo, como no tardaremos en ver.

La autoconciencia desplaza la línea de equilibrio en los dos sistemas oximóricos hacia el polo de la inteligencia; esto explica que, en la segunda parte, don Quijote ya no vea la realidad transformada según el modelo caballeresco y Sancho se haga más independiente de su amo. A partir del encuentro con Sansón Carrasco el escudero demostrará una agudeza superior a la de la primera parte; lo hará con su dominio del lenguaje en el diálogo con su mujer (II, 10) y con su dominio del código caballeresco en el episodio del encantamiento de Dulcinea (II, 10), engendrado, por cierto, en un momento de soliloquio que difícilmente se hubiera podido dar en 1605 , sin la iniciación a los secretos de la autoconsciencia derivados del saberse personaje de un libro ya publicado.

\section{Autoorganización DEL SISTEMA}

Los microsistemas de atributos de un personaje, al confrontarse con los de los demás, dan lugar a diálogos o a acciones y de ahí surgen los diferentes episodios de una novela; más aún, según que predominen unos u otras, se irá configurando un determinado modelo narrativo más centrado en los hechos, como podría ser el Quijote de 1605 - por más que la conversación entre don Quijote y Sancho parezca constante-, o bien más proclive a la confrontación dialéctica de visiones del mundo, con derivaciones hacia una variedad enciclopédica de argumentos, y este sería el caso del Quijote de 1615. Así pues, un elemento del nivel inferior en la jerarquía de sistemas de una narración, un atributo de un personaje en contraste con su opuesto de otro, tiene la potestad de originar un episodio, elemento narrativo de nivel superior, e incluso todo un conjunto de episodios, propios de un modelo concreto de relato - y estamos en un nivel aún superior- que puede definir el subgénero narrativo del texto. En el caso específico, la autoconciencia de los personajes hace que la balanza del oxímoron penda hacia el lado racional, lo cual evitará que don Quijote vea el mundo deformado por su filtro caballeresco y Sancho solo capte una realidad interesada; como consecuencia de ello, habida cuenta también de la aumentada capacidad discursiva de ambos, las aventuras raramente se concluirán con una escena violenta, como en la primera parte, cuando la deformación quijotesca de la realidad provocaba el conflicto, sino que tenderán a la elaboración de sus significados por medio del diálogo entre los personajes.

La inteligencia aumentada del Sancho autoconsciente de 1615 le permite convencer a don Quijote de que Dulcinea está encantada, lo recordaba hace un momento, 
aunque este no vea más que una burda campesina (II, 10). En este temprano episodio de la segunda parte tenemos la pauta para muchos otros; parecen cortados por el mismo patrón, es decir, un patrón que presenta a don Quijote una realidad ya manipulada según el canon caballeresco, la aventura del carro de la Muerte, la doncella, un caballero y el Diablo, que luego se revelarán actores de una compañía teatral (II, 11); la batalla contra el caballero del Bosque y luego el de la Blanca Luna, disfraces bajo los que se oculta Sansón Carrasco (II, 12-16 y 66); y casi todas las burlas del palacio de los duques en las que la constante es siempre la misma: un grupo de figurantes vestidos de personajes caballerescos propone a don Quijote y Sancho una trama preconcebida, como en el cortejo de Merlín (II, 34-35), la farsa de la dueña Dolorida (II, 36) con vuelo en Clavileño incluido (II, 40), los amores de Altisidora (II, 44), el combate contra Tosilos (II, 56), etc.

De este modo, Cervantes ha conseguido dar respuesta a la tercera crítica que le hacían los lectores de 1605, transformando el sistema desde dentro, sobre la base de su capacidad de adaptarse a los estímulos externos, para evitar que los personajes sean frecuentemente apaleados.

El impacto producido por un elemento externo como es la publicación del libro de 1605 en el nivel más bajo del sistema narrativo, el de los semas constitutivos de la personalidad de los protagonistas, ha creado un nuevo equilibrio del que ha surgido un nuevo modelo de episodios y de ahí un subgénero narrativo diferente, más influido por las fiestas y las representaciones cortesanas, como las que podemos ver en el palacio de los duques; no en balde la crítica ha subrayado en diferentes ocasiones la teatralidad intrínseca en muchas de las escenas de la segunda parte (Eximeno y Pujades, 1806: 86; Togeby, 1957: 47, 62; Díaz-Plaja, 1977: 81-162; Syverson-Stork, 1986; Martín Morán, 1986). La modificación del equilibrio en un nivel inferior altera el del inmediatamente superior y así sucesivamente, hasta producir un nuevo equilibrio homeostático del conjunto. Estamos ante un claro ejemplo de autoorganización de los sistemas (Resnick, 2001: 199), como efecto de su capacidad de resiliencia en respuesta a un trauma exterior.

\section{EstATEGIAS DE ESTABILIDAD}

El conjunto de microsistemas en diferentes niveles y sus interacciones del mundo narrativo de 1615 parece bastante coherente en sí mismo, pero Cervantes tenía que conseguir que lo fuera también con el de 1605 , so pena de socavar su autenticidad a los ojos del lector; téngase en cuenta que, si no para cuando la concibiera, al menos para cuando la difundiera, esta segunda parte entraría en competición con la de Avellaneda y no bastaría el nombre de Cervantes en la portada para convencer a su público de que esta era la continuación genuina del libro de 1605. Así que, además de conseguir que los elementos fueran funcionales en el equilibrio del nuevo sistema, 
Cervantes tenía que hacer que se los viera como una evolución de los primigenios y no como su transformación radical. En ese sentido, el repentino cambio de Sancho, con ser una transformación necesaria para desmontar el mecanismo de la violencia como resorte final de los conflictos, podría haber hecho de él un personaje irreconocible para los lectores de la primera parte; su capacidad de acción en situaciones diferentes a las de 1605 exigía explicaciones, que puntualmente llegarán para cada una de las infracciones al equilibrio de sus atributos de antaño; su registro lingüístico elevado es justificado por Teresa, su mujer, por su asiduidad con don Quijote (II, 5), con estas palabras: «—Mirad, Sancho —replicó Teresa—: después que os hicistes miembro de caballero andante habláis de tan rodeada manera que no hay quien os entienda» (II, 5). El propio don Quijote parece estar de acuerdo con Teresa: «-Nunca te he oído hablar, Sancho — dijo don Quijote—, tan elegantemente como ahora, por donde vengo a conocer ser verdad el refrán que tú algunas veces sueles decir: "No con quien naces, sino con quien paces"» (II, 66).

Y, antes aún, había sido el propio Sancho el que había reconocido el ascendente intelectual de su amo sobre él:

—Cada día, Sancho — dijo don Quijote—, te vas haciendo menos simple y más discreto.

—Sí, que algo se me ha de pegar de la discreción de vuesa merced — respondió Sancho-

[...] Rióse don Quijote de las afectadas razones de Sancho, y parecióle ser verdad lo que decía de su emienda, porque de cuando en cuando hablaba de manera que le admiraba (II, 12).

El capítulo II, 5 en que Sancho habla «de rodeada manera» es considerado apócrifo por el ficticio traductor del manuscrito de Cide Hamete, precisamente por la pericia lingüística del escudero; es decir, el traductor - evidentemente un buen conocedor de la lógica de los conjuntos - reconoce como ajeno al sistema de la personalidad del rústico tanta propiedad de lenguaje. Sancho habla con palabras y acentos más propios de su amo, como parece sugerir su mujer cuando achaca su hablar «de rodeada manera» al hecho de que es «miembro de caballero andante». En efecto, en esas circunstancias Sancho, asume funciones propias de don Quijote, como la del «reprochador de voquibles» que él, inmisericorde desmemoriado, practica con los gazapos de su mujer y que tantas veces ha sufrido en su propia piel por el prurito purista del caballero:

—Yo no os entiendo, marido — replicó Teresa—: haced lo que quisiéredes, y no me quebréis más la cabeza con vuestras arengas y retóricas. Y si estáis revuelto en hacer lo que decís...

—Resuelto has de decir, mujer — dijo Sancho—, y no revuelto (II, 5). 
El desarrollo del polo positivo del oxímoron sanchesco ha llegado hasta tal punto con la autoorganización del sistema, que el labrador ignorante puede incluso sustituir a su señor en una de sus funciones. Y eso es lo que sucede también, de algún modo, en el episodio del encantamiento de Dulcinea, donde el Sancho 2.0 invierte los papeles y convence a don Quijote de que por allí andan los encantadores.

En la ínsula, el mayordomo que tenía la misión de montar las burlas provocantes a risa postal de los duques se ve obligado a constatar el notable cambio de Sancho:

—Dice tanto vuesa merced, señor gobernador — dijo el mayordomo-, que estoy admirado de ver que un hombre tan sin letras como vuesa merced, que a lo que creo no tiene ninguna, diga tales y tantas cosas llenas de sentencias y de avisos, tan fuera de todo aquello que del ingenio de vuesa merced esperaban los que nos enviaron y los que aquí venimos. Cada día se veen cosas nuevas en el mundo: las burlas se vuelven en veras y los burladores se hallan burlados (II, 49).

La comparación entre el Sancho de antes y el de ahora, hecha ante el poderoso gobernador Sancho Panza, podría haber sido tomada como una ofensa por este, sino incluso por delación de las verdaderas intenciones de sus señores los duques, los «burladores» de la cita; de ahí que resulte improcedente y fuera del decoro debido al personaje del secretario, al que se supone muy ducho en materia de etiqueta cortesana. Se trata, en realidad, de una de esas intervenciones extemporáneas de un interlocutor de Sancho para motivar, desde el punto de vista de la verosimilitud, la transformación que se ha operado en su capacidad de actuación.

También los cambios de don Quijote son motivados por los demás personajes; concretamente es Sancho quien hace que sus nuevas dotes discursivas con tendencia al enciclopedismo y su mayor lucidez reciban una explicación que las haga aceptables por parte del lector:

- Este mi amo, cuando yo hablo cosas de meollo y de sustancia suele decir que podría yo tomar un púlpito en las manos y irme por ese mundo adelante predicando lindezas; y yo digo dél que cuando comienza a enhilar sentencias y a dar consejos, no sólo puede tomar púlpito en las manos, sino dos en cada dedo, y andarse por esas plazas a ¿qué quieres boca? ¡Válate el diablo por caballero andante, que tantas cosas sabes! Yo pensaba en mi ánima que sólo podía saber aquello que tocaba a sus caballerías, pero no hay cosa donde no pique y deje de meter su cucharada (II, 22).

La confesión final de Sancho sobre la sorpresa que experimenta al ver el amplio espectro de temas que su amo puede abordar revela la función para el sistema que su parlamento cumple: el don Quijote de 1605 corresponde, en efecto, a esa idea de Sancho — «sólo podía saber aquello que tocaba a sus caballerías»—; la 
maravilla actual del escudero justifica el cambio, lo explica y lo hace aceptable para el lector como lógico en el microsistema reorganizado del personaje.

Este nuevo carácter enciclopédico del hidalgo orate, por cierto, va a permitirle ocupar el nicho ecológico, perdón, el ámbito semántico que ha quedado despoblado tras la renuncia a interpolar novelas secundarias en la segunda parte. En ellas el autor ofrecía al lector unas tramas centradas en los temas que no podía tratar en la historia principal, como el amor, el cautiverio, los choques interculturales, etc. La ampliación de funciones de don Quijote sirve para garantizar la riqueza del sistema y la variedad de ambientes semánticos que lo pueblan.

Toda una serie de infracciones al equilibrio homeostático del relato por parte de un personaje son subsanadas por las intervenciones de los otros o por el aparato enunciativo. Cervantes ha distribuido una nueva función, la de «reparadores de la estabilidad del sistema», a varios personajes que la desempeñan integrando en la lógica del relato las infracciones de los demás. Es un procedimiento del que Cervantes ya había echado mano en la segunda salida de don Quijote para subsanar algunos evidentes descuidos del texto, que podían presentarse como una incompatibilidad entre dos elementos diegéticos; por ejemplo, entre un poema insertado, la Canción desesperada de Grisóstomo, y su contexto narrativo; en la Canción Grisóstomo se queja de celos y de ausencia, pero nunca Marcela le había dado motivos ni para lo uno ni para lo otro; así lo hace constar Vivaldo después de dar lectura a los versos del suicida; Ambrosio, el compañero del finado, explica que los dos sentimientos nacían de una suerte de experimento fallido que Grisóstomo había querido hacer y que había que considerarlos poco menos que como una licencia poética $(I, 14)$. Otro descuido corregido con una intervención a posteriori de uno de los personajes implicados en la escena es el de la bacía, primero irreparablemente rota contra el suelo por el estudiante $(\mathrm{I}, 22)$ y poco después restaurada por la magia de la palabra de don Quijote, al reclamársela a Sancho con la explicación de lo sucedido: «Sancho, ¿traes bien guardado el yelmo de Mambrino, que ya vi que le alzaste del suelo cuando aquel desagradecido le quiso hacer pedazos pero no pudo, donde se puede echar de ver la fineza de su temple?» (I, 25).

Ambrosio y don Quijote reparan las costuras del texto y devuelven su funcionalidad a los elementos del sistema que la habían perdido. Es la misma operación que los estimadores del nuevo rumbo de don Quijote y Sancho cumplen cuando aseguran que se trata de una evolución sobre la base caracterial primigenia. La novedad ahora es que el mismo procedimiento de bricolaje textual es usado para reparar la incongruencia entre la personalidad de los protagonistas de 1615 con la de 1605 y así ir construyendo el macrosistema de las dos partes unidas en una sola obra.

El bricolaje textual que repara los descosidos del texto debería ser una función del narrador; en el caso del yelmo, bastaría haber presentado la acción del 
estudiante de otro modo, o bien haber retomado en un segundo momento el episodio y haber corregido sus resultados. Lo mismo cabría decir para la canción de Grisóstomo; no debería haber sido muy difícil para Cervantes sustituir los versos del poema incongruentes con la situación, para que su inclusión en el texto no resultara improcedente. La pretendida evolución de Sancho y don Quijote también podían haber sido presentadas por el narrador directamente, sin la intervención de los personajes. En cambio, el autor despoja de un cometido estructural a su narrador para trasladárselo a los personajes, aumentando así el número de funciones de cada elemento y el número de elementos capaces de desempeñar esa función; como resultado de esta operación, la capacidad de resiliencia del conjunto frente a las posibles agresiones externas resulta potenciada, si tiene razón Mazur (2013: 358) cuando afirma que los sistemas con mayor número de componentes y funciones poseen una mayor capacidad de resiliencia.

\section{El meteorito Avellaneda y la eXtinción del QuiJote}

En una venta, de camino a Zaragoza, don Quijote y Sancho encuentran a dos viajeros que les ponen en las manos un libro - otro más - que cuenta sus aventuras: se trata de la continuación apócrifa de Avellaneda (II, 59). A partir de entonces, una legión de personajes se lanzará a defender los derechos de autor de Cervantes; algunos, como la pareja protagonista (II, 59; y luego aún en II, 62; II, 72; II, 74), Altisidora (II, 70) y el cura (II, 74), ya operativos en la trama; otros, recién llegados, también echan su cuarto a espadas, como don Antonio Moreno (II, 71); otros aún, don Luis y don Jerónimo (II, 59), los viajeros portadores de la noticia, son creados ex profeso para ese papel; y uno, Álvaro Tarfe (II, 72), es sustraído al tordesillesco autor, en aplicación de la ley del Talión, para que certifique ante secretario de ayuntamiento que el verdadero don Quijote es el de Cervantes, él que conoce como nadie al de Avellaneda, siendo como era su mentor; y ya para concluir, en un crescendo de importancia de las entidades ficticias implicadas en el asunto, será el propio Cide Hamete (II, 74) el que se pronuncie en contra del plagiario y en defensa del copyright cervantino; pero no profundizaré en estos temas, puesto que ya me he ocupado de ellos en otro lugar (Martín Morán, 2016).

La constitución de la comunidad anti-Avellaneda ha enriquecido notablemente la biodiversidad del sistema, con la inclusión de nuevos elementos venidos de ámbitos distintos: personajes reutilizados para la ocasión (Altisidora, los protagonistas, el cura), otros inventados ad hoc (don Juan y don Jerónimo), uno sustraído al falsario (Álvaro Tarfe) y, por último, instancias de niveles narrativos superiores (Cide Hamete, el narrador) que intervienen en el discurso. Es conocido en los estudios ecológicos el papel que cumple la biodiversidad en la autoorganización de los sistemas en términos de absorción de los efectos del trauma y construcción 
de un nuevo equilibrio homeostático (Folke, 2006: 257-258), así como sus potencialidades en la afirmación de la estabilidad del sistema y la potenciación de su capacidad de resiliencia (Tilman, 1996); evidentemente Cervantes, ante la tesitura de dar una respuesta a su imitador, supo servirse de las estrategias sistémicas más adecuadas.

\section{REDUNDANCIA}

Todos estos personajes abandonan por un momento sus funciones específicas y asumen como propia la defensa de la autenticidad de los don Quijote y Sancho que tienen delante, frente a los del apócrifo. Nada les iba a ellos en la contienda y, sin embargo, toman posición en favor de quien les dio vida, así sea ficticia, reincidiendo todos, en momentos diferentes, en la misma función; la cual, por cierto, en nada se diferencia de la función prologal que ya atribuíamos a don Quijote y Sancho en sus apostillas en 1615 al libro de 1605. La constitución de una comunidad que reacciona de modo uniforme contra una agresión exterior ha sido vista como una estrategia resiliente en comunidades humanas por Tobim y Whiteford (2002), es decir, como una forma de salvaguardia del sistema, su equilibrio y su funcionalidad, tras la experiencia del trauma.

La defensa de los derechos de propiedad intelectual de Cervantes le correspondía a él mismo y no a sus personajes, tal vez desde el prólogo, donde, en efecto, puntualmente la ejerce: «Quisieras tú [lector] que lo diera del asno [a Avellaneda], del mentecato y del atrevido, pero no me pasa por el pensamiento: castíguele su pecado, con su pan se lo coma y allá se lo haya» (II, prólogo). Desde el punto de vista de la estabilidad del sistema, no deja de ser un enorme lujo el que se concede el autor, al confiar una sola función a tantos elementos; es lo que en la teoría de la complejidad se conoce como «redundancia» (Folke, 2006: 258), una característica que garantiza una mayor resiliencia al conjunto, pues consiente la sustitución de un elemento en caso de que su funcionalidad haya sido comprometida por el estrés traumático, pero que a la vez lo empobrece, pues dificulta el desarrollo de otras funciones. Las investigaciones sobre la redundancia en los ecosistemas han llegado a la conclusión de que, si en determinados estadios puede ser una característica innecesaria, se convierte en un aspecto crucial para la reorganización del conjunto después de un evento traumático (Folke, 2006: 258); y eso es lo que me parece a mí que queda bien patente en el caso de la cuarta fase del equilibrio homeostático del relato del Quijote.

Otra estrategia encaminada a generar estabilidad en un sistema que evidentemente se percibe como tendente a la dispersión, con muchos personajes, varias tramas secundarias y, en consecuencia, muchas funciones divergentes respecto a las líneas de cohesión, es la de reutilizar a algunos personajes para la introducción 
de otros nuevos; de tal suerte, se crea un vínculo entre ellos y sus tramas que reduce la dispersión de la energía funcional en el conjunto. Ricote, después de haber contado su expulsión de España junto a todos los moriscos (II, 54), reaparece como padre de Ana Félix (II, 65); el galeote Ginés de Pasamonte (I, 22) vuelve con un parche en el ojo como maese Pedro (II, 25-27) y el bandolero Roque Guinart envía una carta a su amigo Antonio Moreno (II, 60) a Barcelona, pidiéndole que acoja a don Quijote en su casa (II, 62). La estabilidad queda así garantizada por la inclusión de los episodios en la línea principal de significados; era esta la exigencia estructural cervantina para 1615, tras las críticas por las interpolaciones impertinentes de 1605, como se encarga de aclarar Cide Hamete (II, 44), cuando pide alabanzas por lo que deja de decir, ya que se va a limitar a contar episodios secundarios en los que don Quijote tenga un papel y que además sean breves.

\section{Emblematización de don Quijote y SANCHO}

Antes de Avellaneda, el conflicto de don Quijote con el mundo se centraba en la diferente interpretación del libro de 1605; para don Quijote era una crónica de las gestas de un caballero aventurero, tal vez demasiado ceñida a la historia, sin toda la dimensión poética, de sublimación de los hechos según parámetros universalistas que corrigieran los defectos de la visión extremadamente detallada de la historia, pero crónica caballeresca al fin y al cabo; para los demás, era un libro de burlas sobre alguien que se creía un caballero andante, sin poder serlo por edad, condición económica y salud mental. Tras el trauma Avellaneda, el conflicto desaparece y todos, indiscriminadamente, se centran en defender la autoría de Cervantes, con el pretexto de certificar la autenticidad de los don Quijote y Sancho que tienen delante. La interpretación predominante a partir de entonces es la del libro de éxito con más de treinta mil ejemplares vendidos, según proclama orgullosamente don Quijote ante don Diego de Miranda (II, 16); en la persona del caballero loco y su escudero ven los demás personajes el emblema del libro de Cervantes; en ellos celebran el libro entero, mientras reivindican la paternidad cervantina. En los últimos quince capítulos de la obra, se suceden los encuentros en los que la finalidad última de los interlocutores ya no es la diversión a su costa, como hasta entonces, sino su glorificación con varios actos de reconocimiento y homenaje; no en vano la mayor parte de esos personajes serán también lectores de la primera parte: el bandolero Roque Guinart (II, 60), don Antonio Moreno (II, 62) $\mathrm{y}$, antes aún, los zagales que imitan la Arcadia (II, 58), quienes repiten el agasajo de los dos caminantes hasta en cuatro momentos diferentes. El encuentro con los pastores de la «fingida Arcadia» tiene lugar un capítulo antes que el de la venta con los dos lectores del libro de Avellaneda, pero el hecho de que las ceremonias de homenaje a don Quijote se repitan compulsivamente, sin que de ello se derive 
alguna forma de rebajamiento de su persona ni alguna trama de acciones, me lleva a pensar que en realidad es en este capítulo cuando Cervantes tuvo noticia de la existencia del apócrifo, lo cual no excluye que en ese momento volviera sobre lo ya escrito e introdujera algunas modificaciones en los capítulos anteriores, en respuesta puntual al falsario, como asegura Romero (1990 a y b) que hizo al crear a Sansón Carrasco.

Ese empeño colectivo en pro de la autoría cervantina contamina al narrador, cuando consiente a don Quijote que desmienta el plan narrativo autorizado y avalado por documentos de los que queda constancia en el final de la primera parte, y renuncie a ir a Zaragoza, meta obsesiva de toda la segunda parte hasta este momento del relato, solo para sacar mentiroso a Avellaneda (II, 59). Una simple información de don Juan y don Jerónimo, un elemento que se hubiera podido quedar en el nivel de las relaciones semánticas entre los personajes, trasciende ese nivel de aplicación y origina una serie de episodios que solo tienen la función de celebrar la gloria literaria del don Quijote de Cervantes; las consecuencias de la operación serán de cierta envergadura: el modelo de episodio anterior apuntaba hacia la burla inclusiva del caballero y el escudero, como en el palacio de los duques; a partir de entonces, el objetivo de los varios encuentros, sin abandonar del todo el de la burla inclusiva, será el reconocimiento de la identidad entre la pareja de protagonistas de 1615 y la de 1605; a un nivel aún superior, por decisión de un personaje, se modifica el plan narrativo previsto diez años antes y se cancela la visita a Zaragoza, el único episodio de la segunda parte previsto en la primera. El trauma de la existencia de una continuación apócrifa ha exigido la autoorganización del sistema, mediante un conjunto de reacciones en diferentes niveles, con repercusiones en los niveles inmediatamente superiores, hasta dar lugar a una nueva forma de equilibrio homeostático, con un solo objetivo: reivindicar los derechos de autor de Cervantes.

\section{CONCLUSIÓN}

Sancho y sus transformaciones nos han ofrecido una senda por la que adentrarnos en la lógica de los sistemas narrativos del Quijote. Hemos podido constatar que lo que, según la interpretación de los «quijotizantes», era una evolución de Sancho por influjo de su amo, en realidad parece responder a los efectos de la autoorganización del relato inducida por la acción de un elemento externo. En los cuatro diferentes estadios del sistema narrativo del Quijote, las funciones de los diferentes microsistemas y sus respectivos equilibrios internos han cambiado para adecuarse a la nueva situación. En el segundo, Sancho ha sido el vector que ha producido el trauma, con su apropiación de las funciones ajenas, como una especie invasora en un ecosistema equilibrado; en el tercero y el cuarto, que son los estadios en los 
que la supuesta evolución de Sancho se hace evidente, los cambios en su personalidad responden a un proceso general de reorganización del relato, a raíz de la inclusión en el mismo de dos cataclismos que se han producido en el campo literario, tras la publicación del libro de 1605: las críticas de los lectores del libro y la aparición de la continuación apócrifa de Avellaneda.

La aplicación de una perspectiva sistémica al análisis de las variaciones narrativas del Quijote en los diferentes niveles de su estructura (formación de los personajes, interacción entre ellos, funciones de los personajes y del narrador, modelo de episodio, subgénero narrativo, relación con el campo literario) nos ha permitido comprender mejor la dependencia del medio externo de ciertos fenómenos que antes se veían solo, en una lógica inmanentista, como determinados por la atracción o repulsión de los elementos en el texto. Esta capacidad de autoorganización y resiliencia del Quijote frente a estímulos externos se convertirá, andando el tiempo, en uno de los marcadores genéticos del género de la novela moderna, cuya variabilidad estructural a lo largo de su breve historia se explica gracias a la asimilación de la lección cervantina. 
BIBLIOGRAFÍA

Alonso, Dámaso (1962). «Sancho-Quijote; Sancho-Sancho». En Del Siglo de Oro a este siglo de siglas. Madrid: Gredos, pp. 9-19.

ÅströM, Karl Johan and Richard M. MurRAY (2008). Feedback Systems: an Introduction for Scientists and Engineers. Princeton: Princeton University Press.

Bourdieu, Pierre (1992). Les règles de l'art. Genèse et structure du champ littéraire. Paris: Seuil.

Castiglione, Baldassarre (1965). Il Libro del Cortegiano. Giulio Preti (ed.). Torino: Einaudi.

Castiglione, Baldassarre (1994). El Cortesano. Juan Boscán (trad.) y Mario Pozzi (ed.). Madrid: Cátedra.

Close, Anthony (2001). «¿Cómo se debe remunerar a un escudero, a salario o a merced?: La cuestión del realismo del Quijote». En Isabel Lozano-Renieblas y Juan Carlos Mercado (coords.), Silva. Studia philologica in honorem Isaías Lerner. Madrid: Castalia, pp. 153-65.

Díaz-Plaja, Guillermo (1977). En torno a Cervantes. Pamplona: Universidad de Navarra.

Dotras Bravo, Alexia (2008). Los trabajos cervantinos de Salvador de Madariaga. Historia de una idea doble: sanchificación y quijotización. Alcalá de Henares: Centro de Estudios Cervantinos.

Eximeno y Pujades, Antonio (1806). Apología de Miguel de Cervantes sobre los yerros que se han notado en el Quixote. Madrid: Imprenta de la Administración del Real Arbitrio.

FolKe, Carl (2006). «Resilience: The Emergence of a Perspective for Social-Ecological Systems Analysis». Global Environmental Change, 16, pp. 253-267.

Freud, Sigmund (1978). «Lo ominoso». En Obras completas. José L. Etcheverry (trad.). Buenos Aires: Amorrortu, t. 17, pp. 215-251.

Genette, Gérard (2001). Umbrales. Ciudad de México: Siglo xxi.

Madariaga, Salvador de (1947). Guía del lector del «Quijote». Buenos Aires: Editorial Sudamericana.

Martín Morán, José Manuel (1986). «Los escenarios teatrales del Quijote». Anales Cervantinos, 24, pp. 27-46.

MARTín MorÁn, José Manuel (1992). «Don Quijote está sanchificado; el des-sanchificador que lo re-quijotice...». Bulletin Hispanique, 94: 1, pp. 75-118.

Martín Morán, José Manuel (2004). «El salario de Sancho Panza: trasfondo político-literario de una reivindicación sindical». En Ignacio Arellano y Marc Vitse (coords.), Modelos de vida en la España del Siglo de Oro. Madrid / Frankfurt am Main: Iberoamericana / Vervuert, pp. 367-394.

Martín Morán, José Manuel (2016). «El Quijote de 1615. Un modelo de resiliencia para la novela moderna». En Françoise Gilbert, Marina Mestre Zaragoza y Philippe Meunier (coords.), «A vueltas con el "Quijote”. 2015-2016: nuevos enfoque». Criticón, 127, pp. 77-91.

Martínez Bonati, Félix (1978). «El Quijote: Juego y significación». Dispositio, 3, 9, pp. 315-336.

MAzur, Laurie (2013). «Cultivating Resilience in a Dangerous World». En Worldwatch Institute, The State of the World 2013: Is Sustainability Still Possible? Washington / Covelo / London: Island Press, pp. 353-362. 
Molno, Maurice (1976). Cervantes: raices folklóricas. Madrid: Gredos.

Redondo, Augustin (1978). «Tradición carnavalesca y creación literaria. Del personaje de Sancho Panza al episodio de la ínsula Barataria en el Quijote». Bulletin Hispanique, 80: 1-2, pp. 39-70.

RESNICK, Mitchel (2001). Tortugas, termitas y atascos de tráfico. Barcelona: Gedisa.

Romero, Carlos (1990a). «Nueva lectura de El retablo de maese Pedro». En VV. AA. (coords.), Actas del I Coloquio Internacional de la Asociación de Cervantistas. Barcelona: Anthropos, pp. 95-130.

Romero, Carlos (1990b). «La invención de Sansón Carrasco». En VV. AA. (coords.), Actas del II Coloquio Internacional de la Asociación de Cervantistas. Barcelona: Anthropos, pp. 27-69.

Russell, Peter E. (1978). «Don Quijote y la risa a carcajadas». En Temas de La Celestina y otros estudios. Barcelona: Ariel, pp. 406-440.

SÁnchez Rivero, Ángel (1927). «Las ventas del Quijote». Revista de Occidente, 17, pp. 1-20 y 291-315.

SAVu-Lopez, Paolo (1913). Cervantes. Napoli: Ricciardi.

SLETSJÖE, Leif (1961). Sancho Panza, hombre de bien. Madrid: Ínsula.

Socrate, Mario (1974). Prologhi al Don Chisciotte. Venezia / Padova: Marsilio.

Syverson-Stork, Jill (1986). Theatrical Aspects of the Novel: A Study of Don Quixote. Valencia: Albatros Hispanófila.

Tobin, Graham A. and Linda M. Whiterford (2002). «Community Resilience and Volcano Hazard: the Eruption of Tungurahua and Evacuation of the Faldas in Equador». Disaster, 26: 1, pp. 28-48.

Toffanin, Giuseppe (1920). La fine dell'umanesimo. Torino: Fratelli Bocca.

TogeBy, Knud (1957). La composition du roman Don Quijote. Copenhague: Munskgaard.

Tilman, David (1996). «Biodiversity: population versus ecosystem stability». Ecology, 77, pp. $350-363$.

Watzlawick, Paul, Janet Helmick Beavin y Don D. Jackson (1985). Teoría de la comunicación humana. Interacciones, patologías y paradojas. Barcelona: Herder.

Recibido: 01/06/2021

Aceptado: 05/07/2021 


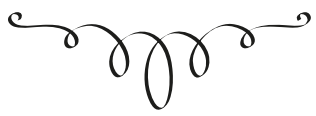

\section{LA QUiJotiZACIÓN DE SANCho y LA AUTOORGANIZACIÓN DE LOS SISTEMAS}

RESUMEN: Sancho en la ínsula gobierna como un Salomón, piensan sus paisanos. Y efectivamente, no cabe duda de que en el episodio de Barataria el escudero hace gala de inteligencia, perspicacia y prudencia, cualidades que hasta entonces no formaban parte de su acervo. La explicación de tan extraordinario cambio habría que buscarla, en opinión de Madariaga y otros críticos, en la constante interacción con su amo; la mutua influencia de los dos andantes habría restituido a don Quijote a la realidad del mundo cotidiano y proyectado a Sancho a unas esferas del ser social antes inalcanzables para él. Esta visión de las relaciones entre amo y escudero, a mi ver, pierde de vista el hecho de que ambos, además de relacionarse entre sí, tienen que hacerlo con los demás y con el contexto que los envuelve; en una palabra, no los considera como elementos de un sistema, condicionados por los cambios del mismo y por sus procesos de autoorganización en respuesta a determinados estímulos externos. Este trabajo acepta como base de partida justamente ese aserto y propone la capacidad de resiliencia de los dos personajes, y por extensión de la novela de Cervantes, a los traumas del ambiente externo como la clave para la instauración en 1615 de un nuevo equilibrio homeostático del sistema narrativo del que surgirá incluso un nuevo modelo de novela.

PALABRAS CLAVE: quijotización y sanchificación, binomio, sistema, autoorganización, resiliencia, novela moderna.

\section{SANCHO'S QUIXOTIZATION AND THE SELF-ORGANIZATION OF SYSTEMS}

ABstract: Sancho on the island rules like a Solomon, think the countrymen of him. And indeed, there is no doubt that in the Barataria episode the squire shows intelligence, insight and prudence, qualities that until then were not part of his personality. The explanation for such an extraordinary change should be sought, in the opinion of Madariaga and other critics, in the constant interaction with his master; the mutual influence of the two «andantes» would have restored Don Quixote to the reality of the everyday world and projected Sancho into spheres of social being previously unattainable for him. This vision of the relationship between master and squire, in my view, loses sight of the fact that both, in addition to relating to each other, have to do so with others and with the context that surrounds them; in a word, it does not consider them as elements of a system, conditioned by its changes and by its self-organizing processes in response to certain external stimuli. This paper accepts as a starting point precisely this assertion and proposes the resilience of the two characters, and by extension of Cervantes's novel, to the traumas of the external environment as the key to the establishment in 1615 of a new homeostatic balance of the narrative system from which even a new model of novel will emerge.

KeYwords: Quixotization and Sanchification, binomial, system, self-organization, resilience, modern novel. 